\title{
Article \\ Effects of Different Application Times of Silver Diamine Fluoride on Mineral Precipitation in Demineralized Dentin
}

\author{
Surapong Srisomboon ${ }^{1}$, Matana Kettratad ${ }^{1} \oplus$, Phakkhananan Pakawanit ${ }^{2}$, Catleya Rojviriya ${ }^{2}$, \\ Prathip Phantumvanit ${ }^{3}$ and Piyaphong Panpisut ${ }^{3,4, *(D)}$ \\ 1 Unit of Gerodontology, Faculty of Dentistry, Thammasat University, T. Klong 1, A. Klongluang, \\ Pathum Thani 12120, Thailand; surapong.sri@dome.tu.ac.th (S.S.); pmatana@staff.tu.ac.th (M.K.) \\ 2 Synchrotron Light Research Institute (Public Organization), 111 University Avenue, Muang District, \\ Nakhon Ratchasima 30000, Thailand; phakkhananan@slri.or.th (P.P.); catleya@slri.or.th (C.R.) \\ 3 Faculty of Dentistry, Thammasat University, T. Klong 1, A. Klongluang, Pathum Thani 12120, Thailand; \\ prathipphan@gmail.com \\ 4 Thammasat University Research Unit in Dental and Bone Substitute Biomaterials, Thammasat University, \\ T. Klong 1, A. Klongluang, Pathum Thani 12120, Thailand \\ * Correspondence: panpisut@staff.tu.ac.th
}

check for updates

Citation: Srisomboon, S.; Kettratad, M.; Pakawanit, P.; Rojviriya, C.; Phantumvanit, P.; Panpisut, P. Effects of Different Application Times of Silver Diamine Fluoride on Mineral Precipitation in Demineralized Dentin. Dent. J. 2021, 9, 70. https:// doi.org/10.3390/dj9060070

Academic Editors: Arkadiusz Dziedzic and Rahiotis Christos

Received: 3 April 2021

Accepted: 9 June 2021

Published: 14 June 2021

Publisher's Note: MDPI stays neutral with regard to jurisdictional claims in published maps and institutional affiliations.

Copyright: (c) 2021 by the authors. Licensee MDPI, Basel, Switzerland. This article is an open access article distributed under the terms and conditions of the Creative Commons Attribution (CC BY) license (https:/ / creativecommons.org/licenses/by/ $4.0 /)$.

\begin{abstract}
Silver diamine fluoride (SDF) is a cost-effective method for arresting active dental caries. However, the limited cooperation of patients may lead to an SDF application time that is shorter than the recommended 1-3 min for carious lesions. Therefore, the aim of this study was to assess the effect of different application times of SDF on the degree of mineral precipitation in demineralized dentin. Demineralized dentin specimens from permanent maxillary molars were treated by applying $38 \%$ SDF for 30, 60, or $180 \mathrm{~s}$. Water was applied in the control group. The specimens were immersed in simulated body fluid for 2 weeks, and the mineral precipitation in demineralized dentin was then analyzed using FTIR-ATR, SEM-EDX, and synchrotron radiation X-ray tomographic microscopy (SRXTM). The FTIR-ATR results showed a significant increase in mineral precipitation in the $180 \mathrm{~s}$ group after 1 week. However, after 2 weeks, the SRXTM images indicated comparable mineral density between the 30,60, and 180 s groups. The precipitation of silver chloride and calcium phosphate crystals that occluded dentinal tubules was similar in all experimental groups. In conclusion, an application time of either 30,60, or 180 s promoted a comparable degree of mineral precipitation in demineralized dentin.
\end{abstract}

Keywords: silver diamine fluoride; dental caries; application time; demineralization; remineralization; mineral density

\section{Introduction}

Dental caries remains the most common preventable chronic disease that affects people worldwide. Almost 2.3 billion adults and 532 million children are reported to have untreated dental caries [1]. The treatment of dental caries constitutes a high economic burden in many countries and requires long-term management. Non-invasive or minimally invasive techniques are regarded as cost-effective methods for the management of dental caries [2], and one such method is the use of silver diamine fluoride (SDF) [3,4], which has been reported to prevent $61 \%$ [5] and 71\% [6] of caries in children and adults, respectively.

The most commonly used SDF products contain 38\% SDF ( 44,800 ppmF) [7]. SDF solution contains fluoride and silver ions that are stabilized by di-ammine groups, and its main actions are the promotion of remineralization and the inactivation of active carious lesions. Silver ions exert strong antimicrobial effects and reduce collagen degradation by inhibiting dentin collagenases [8,9]. Additionally, silver ions react with phosphate or chloride ions, resulting in the formation of silver salts with low solubility, which hardens soft carious lesions [9]. This subsequently results in a black metallic stain on the tooth 
surface [10]. The high fluoride concentration in SDF is also intended to promote dentin remineralization through the formation of fluorohydroxyapatite and calcium fluoride [11]. Additionally, the formation of ammonium compounds may have an acid-buffering effect and increase the alkalinity of the environment, which can facilitate the precipitation of mineral apatite [12]. Therefore, the use of SDF reduces further tooth demineralization and facilitates the functional recovery of carious lesions [13].

The application technique of SDF is simple, which makes it suitable for controlling active caries in patients who have special care needs or those who are less cooperative [14] The application time of SDF ranges from $10 \mathrm{~s}$ to $3 \mathrm{~min}$ [15], and at least 1-3 min has been suggested to allow the solution to adsorb to the lesions [16,17]. However, the application time of SDF can vary, and it may be shorter than the recommendation when patient cooperation is limited. According to previous studies, the application time may not be related to the success of the treatment [16]. However, the possible reasons or mechanisms that explain this observation are unclear, and supporting evidence is limited. Therefore, the aim of this in vitro study was to assess the effect of different SDF application times (30, 60 , and $180 \mathrm{~s}$ ) on mineral precipitation in demineralized dentin. The null hypothesis in the current study was that the application time does not affect the mineral precipitation in demineralized dentin.

\section{Material and Methods}

\subsection{Specimen Preparation}

The use of extracted human teeth was approved by the Ethics Review Sub-Committee for Research Involving Human Research Subjects of Thammasat University (approval number: 150/2562). In total, 13 extracted third permanent maxillary molars with a similar size and no visible caries were collected from Thammasat University Hospital, Pathum Thani, Thailand. The collected teeth were stored for less than 30 days in $0.1 \%$ thymol solution at $23^{\circ} \mathrm{C}$ prior to the test.

Each tooth was cut horizontally and perpendicular to dentinal tubules at $\sim 2 \mathrm{~mm}$ below the occlusal surface using a cutting machine (Accutom 50, Struers, Cleveland, $\mathrm{OH}$, USA) to produce dentin slices ( $2.0 \pm 0.1 \mathrm{~mm}$ in thickness). Then, the surfaces of the specimens were polished with microfine 4000-grit abrasive papers (Tegramin, Struers, Cleveland, $\mathrm{OH}, \mathrm{USA}$ ) and cleaned with an ultrasonic bath for $5 \mathrm{~min}$. Each dentin slice was then divided into four pieces using a diamond bur to produce a total of 52 dentin specimens. The specimens were demineralized using a simplified method by placing them in a tube containing $10 \mathrm{~mL}$ of $17 \%$ ethylenediaminetetraacetic acid (EDTA, Faculty of Dentistry, Chulalongkorn University, Bangkok, Thailand) for $72 \mathrm{~h}$ to produce mineraldepleted dentin $[10,18]$. The specimens were rinsed with deionized water and blotted dry. Deionized water (control group) or SDF (253,900 ppmAg and 44,800 ppmF, Topamine ${ }^{\mathrm{TM}}$, Dentalife, Victoria, Australia) was applied to specimens from each tooth using the following protocols ( $n=13$ /group) (Figure 1).

1. Group 1 (control): $25 \mu \mathrm{L}$ of deionized water was applied;

2. Group 2 (30 s): $25 \mu \mathrm{L}$ of SDF was applied and left for $30 \mathrm{~s}$;

3. Group $3(60 \mathrm{~s}): 25 \mu \mathrm{L}$ of SDF was applied and left for $60 \mathrm{~s}$;

4. Group 4 (180 s): $25 \mu \mathrm{L}$ of SDF was applied and left for $180 \mathrm{~s}$.

The specimens were then rinsed with deionized water for $10 \mathrm{~s}$. They were then placed in a tube containing $5 \mathrm{~mL}$ of simulated body fluid (SBF) prepared according to BS ISO 23317:2014 [19]. The SBF solution was prepared by dissolving reagent-grade $\mathrm{NaCl}$ (Sigma-Aldrich, St. Louis, $\mathrm{MO}, \mathrm{USA}), \mathrm{NaCO}_{3}$ (Sigma-Aldrich), $\mathrm{KCl}$ (Sigma-Aldrich), $\mathrm{K}_{2} \mathrm{HPO}_{4} \cdot 3 \mathrm{H}_{2} \mathrm{O}$ (Sigma-Aldrich), $\mathrm{MgCl}_{2} \cdot 6 \mathrm{H}_{2} \mathrm{O}$ (Sigma-Aldrich), $\mathrm{CaCl}_{2}$ (Sigma-Aldrich), and $\mathrm{Na}_{2} \mathrm{SO}_{4}$ (Sigma-Aldrich) in deionized water. The $\mathrm{pH}$ of the solution was adjusted using tris-hydroxymethyl (Sigma-Aldrich) and $1 \mathrm{M} \mathrm{HCl}$. SBF contains the same phosphate concentration as blood plasma or body fluid $(\mathrm{pH}=7.40)$ [20]. The use of SBF is intended to mimic the oral environment in which SDF adsorbs to dentin when exposed to dentinal 
fluid. The specimens were incubated at $37^{\circ} \mathrm{C}$ for up to 2 weeks without replacing SBF with fresh solution.

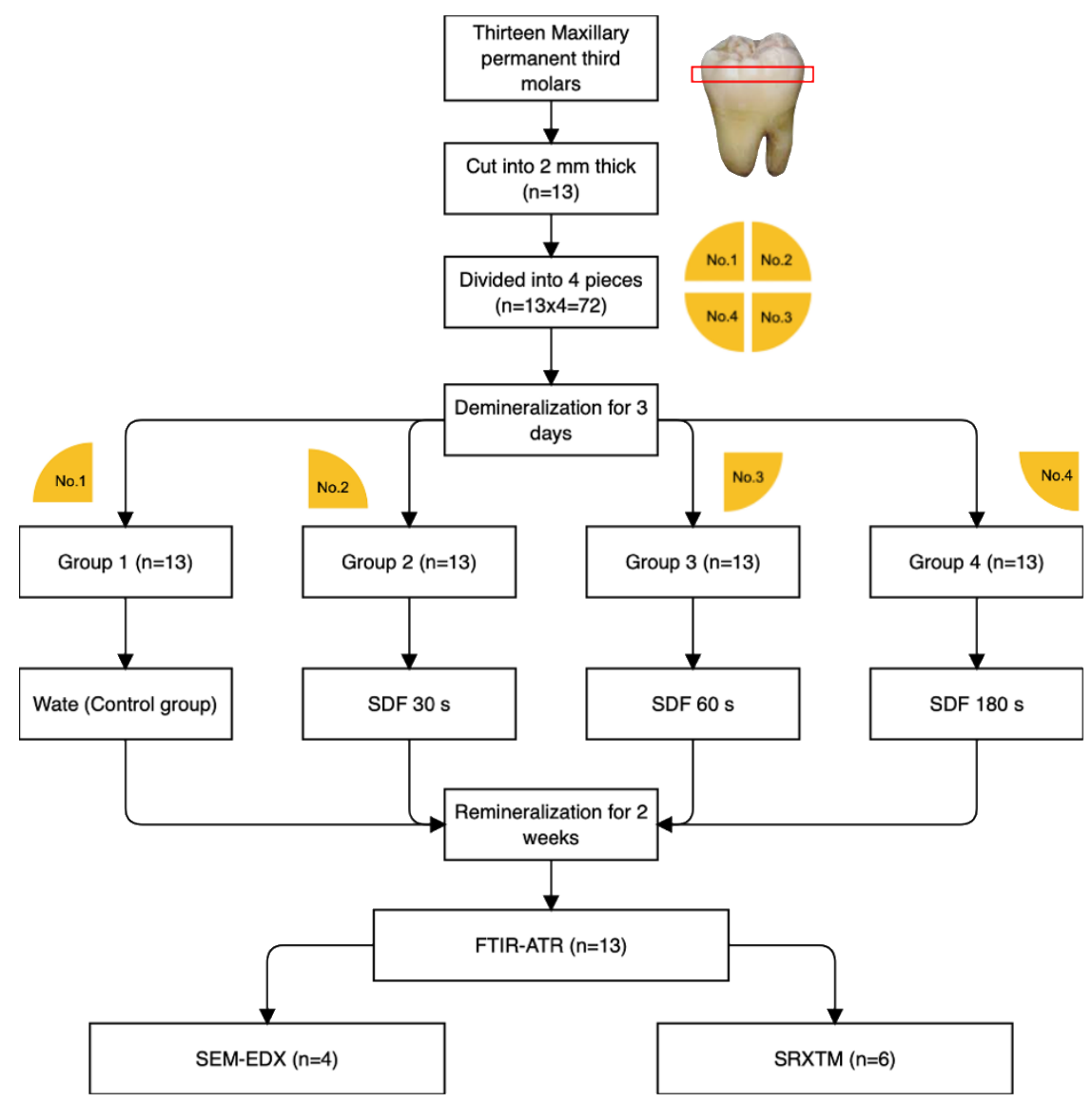

Figure 1. Flowchart representing the methods used in the current study.

\subsection{Assessment of Mineral Apatite Precipitation Using FTIR-ATR}

A Fourier-transform infrared spectrometer (FTIR, Nicolet iS5, Thermo Fisher Scientific, Waltham, MA, USA) equipped with attenuated total reflection (ATR, ID7, Thermo Fisher Scientific) was used to assess the apatite formation on the demineralized dentin using a protocol modified from previous studies $(n=13)$ [21-24]. FTIR spectra of the specimens before and after immersion in SBF for 1 day, 1 week, and 2 weeks were obtained. The specimens were blotted dry and placed on the ATR diamond. FTIR spectra in the region of $700-4000 \mathrm{~cm}^{-1}$ with a resolution of $8 \mathrm{~cm}^{-1}$ and 12 repetitions were recorded from the bottom surface (Figure 2A).

Peaks representing mineral apatite $\left(1024 \mathrm{~cm}^{-1}, \mathrm{PO}_{4}{ }^{3-}\right.$ stretch) were detected [25]. Furthermore, peaks representing type I collagen in dentin, such as $1636 \mathrm{~cm}^{-1}(\mathrm{C}=\mathrm{O}$ stretch, amide I) [26], 1538 (amide II, C-N stretch) [27], and $3300 \mathrm{~cm}^{-1}$ (amide A and amine $\mathrm{N}-\mathrm{H})$ [28], were also recorded. The ratio of the FTIR peak area at $1024 \mathrm{~cm}^{-1}\left(\mathrm{Abs}_{1024}\right)$, which represents the phosphate group in hydroxyapatite, versus the peak area at $1636 \mathrm{~cm}^{-1}$, which represents collagen, was obtained using OMNIC Series software (Thermo Fisher Scientific, Waltham, MA, USA). The mineral/matrix ratio, or $\mathrm{Abs}_{1024} / \mathrm{Abs}_{1636}$, was then calculated (Figure 2B). An increase in the $\mathrm{Abs}_{1024} / \mathrm{Abs}_{1636}$ ratio indicates an increase in mineral precipitation (remineralization) in demineralized dentin. 

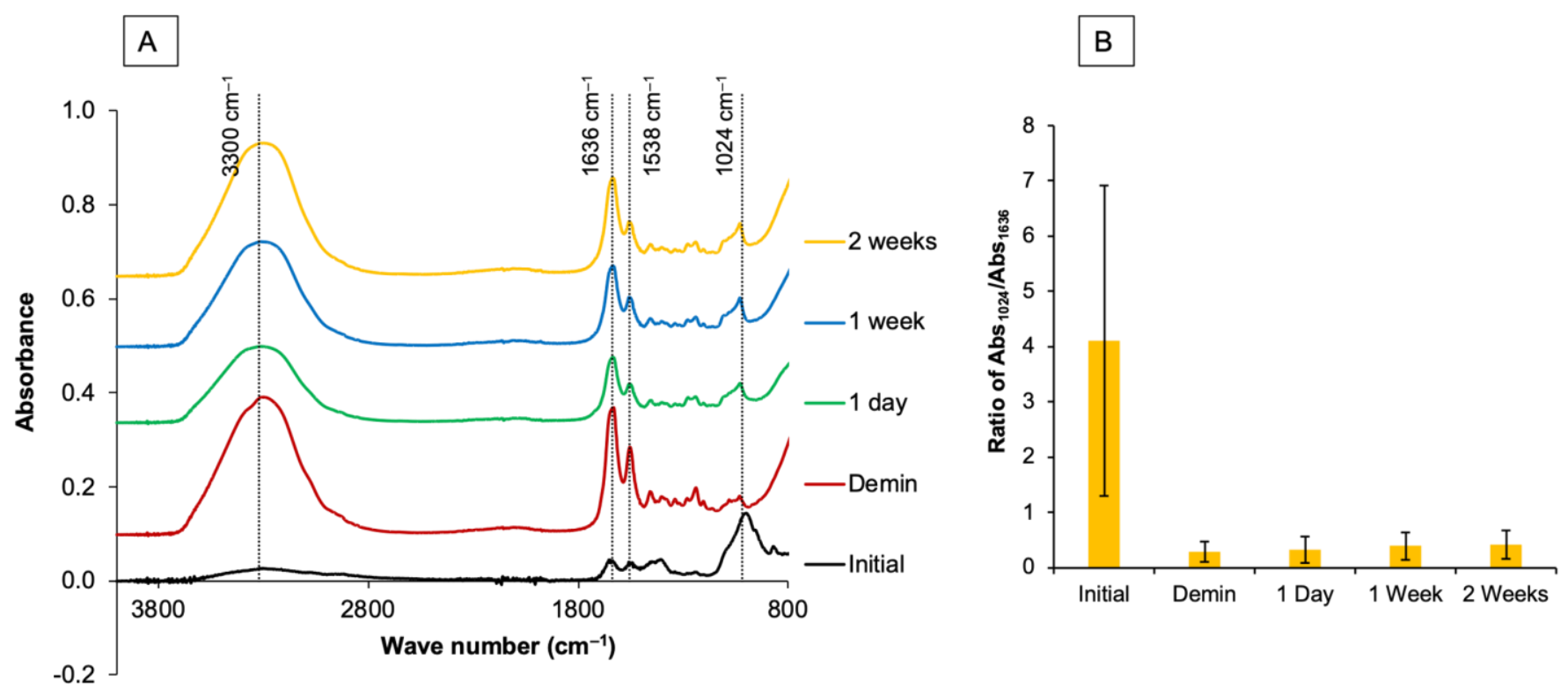

Figure 2. (A) Example of FTIR spectra of a specimen from the $60 \mathrm{~s}$ group prior to the demineralization process. A strong peak of the phosphate group in mineral apatite $\left(1024 \mathrm{~cm}^{-1}, \mathrm{PO}_{4}{ }^{3-}\right.$ stretch) was detected. After demineralization, peaks representing type I collagen, such as $1636 \mathrm{~cm}^{-1}$ (C=O stretch, amide I), 1538 (amide II, C-N stretch), and $3300 \mathrm{~cm}^{-1}$ (amide A), were stronger than the peak attributable to apatite. (B) The area of the FTIR peak at $1024 \mathrm{~cm}^{-1}$ versus $1636 \mathrm{~cm}^{-1}$ was then obtained to determine the mineral precipitation in dentin.

\subsection{Assessment of Surface Mineral Precipitation Using SEM-EDX}

After immersion in SBF for 2 weeks, representative specimens $(n=4)$ were randomly selected and blotted dry. The specimens were sputter-coated with gold using a sputtercoating machine (Q150R ES, Quorum Technologies, East Sussex, UK) with a current of $23 \mathrm{~mA}$ for $45 \mathrm{~s}$. The specimen surface was then examined using a scanning electron microscope (SEM, JSM 7800F, JEOL Ltd., Tokyo, Japan) using an accelerating voltage of $5 \mathrm{kV}$ with a magnification of $2500 \times$ to $20,000 \times$. An elemental analysis [29] was performed using a dispersive X-ray spectrometer (EDX, X-Max 20, Oxford Instruments, Abingdon, UK) to analyze the elemental composition $(\mathrm{Ca}, \mathrm{P}, \mathrm{Ag}$, or $\mathrm{F})$ of the precipitate on representative specimens. The measurement was taken from three different areas of the precipitate with a magnification of 20,000 $\times$ and a beam voltage set at $5 \mathrm{kV}$. Data were analyzed using INCA software version 5.05 (ETAS, Stuttgart, Germany).

\subsection{Assessment of the Degree of Mineral Precipitation (Mineral Density) Using Synchrotron Radiation X-ray Tomographic Microscopy (SRXTM)}

After immersion for 2 weeks, the specimens were randomly selected and blotted dry $(n=6)$. Synchrotron radiation X-ray tomographic microscopy (SRXTM) was employed to quantify the amount of mineral precipitation in demineralized dentin. The experiment was carried out at the XTM beamline (BL1.2W: X-ray imaging and tomographic microscopy) at the Synchrotron Light Research Institute (public organization) in Thailand. The synchrotron radiation was generated from a 2.2 Tesla multipole wiggler in the $1.2 \mathrm{GeV}$ Siam Photon Source. For the data collection, each dentin specimen was held in a polyimide tube and mounted on a rotary stage. A total of $900 \mathrm{X}$-ray projections were obtained at $0-180^{\circ}$ with an angular increment of $0.2^{\circ}$. Tomography images were collected with a filtered polychromatic $X$-ray beam at a mean energy of $14 \mathrm{keV}$ at a distance of $32 \mathrm{~m}$ from the source.

The $X$-ray projections were obtained using a detection system equipped with a $200 \mu \mathrm{m}$ thick YAG: Ce scintillator, a white-beam microscope (Optique Peter, Lentilly, France), and a pco.edge $5.5 \mathrm{sCMOS}$ camera $(2560 \times 2160$ pixels, 16 bits $)$. All tomographic scans were acquired at a pixel size of $1.44 \mu \mathrm{m}$. The $\mathrm{X}$-ray projections were normalized by flat-field correction with open-beam and dark images. The tomograms were reconstructed using 
Octopus Reconstruction software (TESCAN, Gent, Belgium) [30]. The 3D volume representation was produced using Drishti software [31]. The degree of mineral precipitation was determined from the proportion of dense mineral areas in radiolucent demineralized dentin. Each specimen was measured at 3 different areas chosen at random $(\sim 10 \times 10 \mu \mathrm{m})$. The measurement in each area was performed for 250 slices $(250 \times 1.44 \mu \mathrm{m}=360 \mu \mathrm{m})$. The mineral density (vol\%) was determined by calculating the radiodense areas in the measured volume using Octopus Analysis software (TESCAN, Gent, Belgium).

\subsection{Statistical Analysis}

Data were analyzed using Prism9 for Mac OS (GraphPad Software, San Diego, CA, USA). The normality of data was assessed using the Shapiro-Wilk test. The changes in the $\mathrm{Abs}_{1024} / \mathrm{Abs}_{1636}$ ratio of each group based on the immersion time were analyzed using the Friedman test followed by Dunn's multiple comparison. The differences in the $\mathrm{Abs}_{1024} / \mathrm{Abs}_{1636}$ ratio of each group were determined using the Kruskal-Wallis test followed by Dunn's multiple comparison. The mineral density result was analyzed using one-way ANOVA followed by Tukey's multiple comparisons. All $p$ values below 0.05 were considered statistically significant. The post hoc power analysis was performed using G*Power version 3.1.9.6 (University of Dusseldorf, Dusseldorf, Germany). The effect size [32] of each experiment was calculated from the results obtained in the current study, which demonstrated that the sample size used in each test exhibited a power $>0.95$ at alpha $=0.05$.

\section{Results}

\subsection{Assessment of Mineral Precipitation Using FTIR-ATR}

The median $\mathrm{Abs}_{1024} / \mathrm{Abs}_{1636}$ ratios of the control group after $24 \mathrm{~h}, 1$ week, and 2 weeks were comparable $(p>0.05)$ (Table 1). For the 30 s group, the median $\mathrm{Abs}_{1024} / \mathrm{Abs}_{1636}$ ratio increased from 0.282 to 0.308 after 2 weeks. However, the $\mathrm{Abs}_{1024} / \mathrm{Abs}_{1636}$ ratios obtained at each time point were comparable $(p>0.05)$. For the $60 \mathrm{~s}$ group, a significant increase in the $\mathrm{Abs}_{1024} / \mathrm{Abs}_{1636}$ ratio was observed after 2 weeks $(p=0.0143)$. For the $180 \mathrm{~s}$ group, a significant increase in the $\mathrm{Abs}_{1024} / \mathrm{Abs}_{1636}$ ratio was observed after 1 week $(p=0.0029)$.

Table 1. The $\mathrm{Abs}_{1024} / \mathrm{Abs}_{1636}$ ratios (median, min-max) obtained from specimens in each group for up to 2 weeks ( $n=13$ ). Lower- and uppercase letters within the same row and same column, respectively, indicate significant differences $(p<0.05)$.

\begin{tabular}{|c|c|c|c|c|c|c|}
\hline $\begin{array}{l}\text { Groups/ } \\
\text { Time }\end{array}$ & $\begin{array}{c}0 \mathrm{~h} \\
\text { Median } \\
\text { (Min,Max) }\end{array}$ & $\begin{array}{c}24 \mathrm{~h} \\
\text { Median } \\
\text { (Min,Max) }\end{array}$ & $\begin{array}{c}1 \text { Week } \\
\text { Median } \\
\text { (Min,Max) }\end{array}$ & $\begin{array}{c}2 \text { Weeks } \\
\text { Median } \\
\text { (Min,Max) }\end{array}$ & $\begin{array}{l}\text { Friedman } \\
\text { Statistics }\end{array}$ & $p$ Values \\
\hline Control (Water) & $\begin{array}{c}0.134 \\
(0.070,0.453)\end{array}$ & $\begin{array}{c}0.133 \\
(0.07,0.35)\end{array}$ & $\begin{array}{c}0.123 \\
(0.07,0.38)^{\mathrm{B}, \mathrm{C}}\end{array}$ & $\begin{array}{c}0.117 \\
(0.07,0.38) \\
\text { D,E }\end{array}$ & 11.34 & $>0.05$ \\
\hline $\begin{array}{l}\text { SDF } \\
30 s\end{array}$ & $\begin{array}{c}0.282 \\
(0.080,0.722)\end{array}$ & $\begin{array}{c}0.244 \\
(0.093,0.928)\end{array}$ & $\begin{array}{c}0.318 \\
(0.101,0.949)^{B}\end{array}$ & $\begin{array}{c}0.308 \\
(0.104,0.935) \mathrm{D}\end{array}$ & 5.215 & $>0.05$ \\
\hline $\begin{array}{l}\text { SDF } \\
60 \mathrm{~s}\end{array}$ & $\begin{array}{c}0.116^{\mathrm{a}} \\
(0.068,0.613)\end{array}$ & $\begin{array}{c}0.173 \\
(0.040,0.593)\end{array}$ & $\begin{array}{c}0.148 \\
(0.084,0.804)\end{array}$ & $\begin{array}{c}0.206^{\mathrm{a}} \\
(0.088,0.957)\end{array}$ & 0.48 & a 0.0143 \\
\hline $\begin{array}{l}\text { SDF } \\
180 \mathrm{~s}\end{array}$ & $\begin{array}{c}0.180^{\mathrm{a}, \mathrm{b}} \\
(0.048,0.421)\end{array}$ & $\begin{array}{c}0.202^{\mathrm{c}, \mathrm{d}} \\
(0.061,0.701)\end{array}$ & $\begin{array}{c}0.316^{\mathrm{a}, \mathrm{c}} \\
(0.093,0.832)^{\mathrm{C}}\end{array}$ & $\begin{array}{c}0.250^{\mathrm{b}, \mathrm{d}} \\
(0.126,0.895)^{\mathrm{E}}\end{array}$ & 20.54 & $\begin{array}{l}\text { a } 0.0029 \\
\text { b } 0.0085 \\
\text { c } 0.0085 \\
\text { d } 0.0234\end{array}$ \\
\hline Kruskal-Wallis statistics & 2.667 & 8.021 & 12.80 & 16.12 & & \\
\hline$p$ values & $>0.05$ & A 0.0461 & $\begin{array}{c}\text { В } 0.168 \\
\text { C } 0.0083\end{array}$ & $\begin{array}{l}\text { D } 0.0023 \\
\text { E } 0.0046\end{array}$ & & \\
\hline
\end{tabular}

At $0 \mathrm{~h}$, the median $\mathrm{Abs}_{1024} / \mathrm{Abs}_{1636}$ ratios of all groups were comparable (Table 1). After $24 \mathrm{~h}$, the median $\mathrm{Abs}_{1024} / \mathrm{Abs}_{1636}$ ratio of the 30 s group was significantly higher than that of the control group $(p=0.0461)$. After 1 week, the median $\mathrm{Abs}_{1024} / \mathrm{Abs}_{1636}$ ratios of both the 30 and $180 \mathrm{~s}$ groups were significantly higher than that of $0 \mathrm{~h}(p<005)$. Similarly, 
the median $\mathrm{Abs}_{1024} / \mathrm{Abs}_{1636}$ ratios of both the 30 and 180 s groups after 2 weeks were also significantly higher than that of the control group $(p<0.05)$.

The changes in the $\mathrm{Abs}_{1024} / \mathrm{Abs}_{1636}$ ratio from $0 \mathrm{~h}$ to 2 weeks in each group are demonstrated in Figure 3. The $\mathrm{Abs}_{1024} / \mathrm{Abs}_{1636}$ ratio obtained from the control group $(-0.035)$ was significantly lower than that of the $30(0.077)(p=0.0337), 60(0.068)(p=0.0130)$, and $180 \mathrm{~s}(0.106)(p=0.0027)$ groups. However, the values obtained from the 30,60 , and $180 \mathrm{~s}$ groups were comparable $(p>0.05)$.

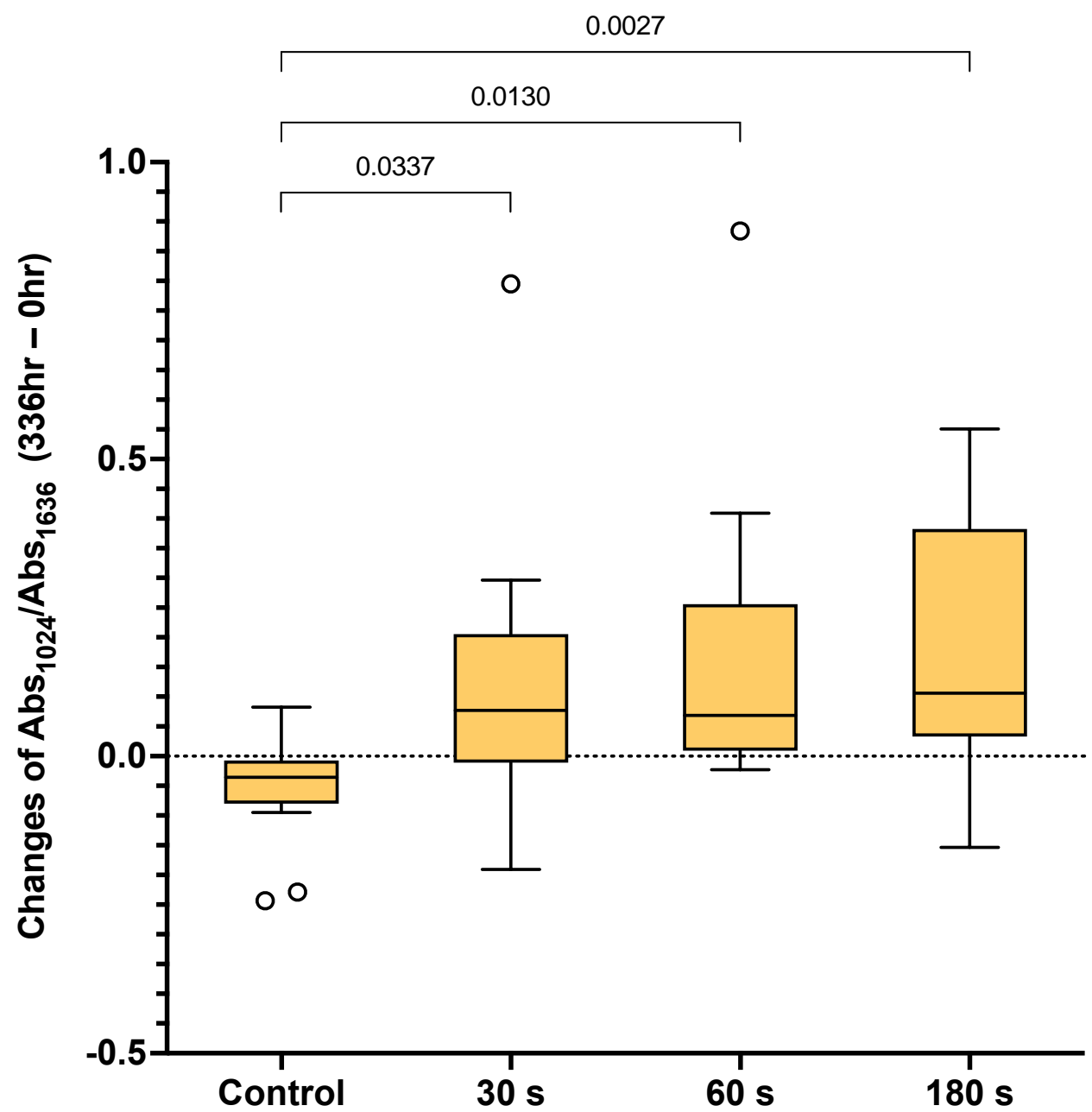

Figure 3. Box plots of the differences in $\mathrm{Abs}_{1024} / \mathrm{Abs}_{1636}$ after 2 weeks compared with the initial value ( 336 vs. $0 \mathrm{~h}$ ). The boxes represent the first quartile (Q1) to the third quartile (Q3), the horizontal lines in the box represent the median, and the whiskers represent the maximum and minimum values $(n=13)$. The line indicates $p<0.05$. Circles are outliers.

\subsection{Assessment of Surface Mineral Precipitation Using SEM-EDX}

The SEM images of specimens treated with water showed patent dentinal tubules without mineral precipitation (Figure 4A). The peritubular dentin and dentinal tubules of specimens from the 30,60 , and $180 \mathrm{~s}$ groups were filled with precipitated crystals (Figure 4B-D). Precipitates containing Ca, P, and F were detected (Figure 5A). Additionally, crystals consisting of $\mathrm{Ag}$ and $\mathrm{Cl}$ were also observed (Figure 5B). 

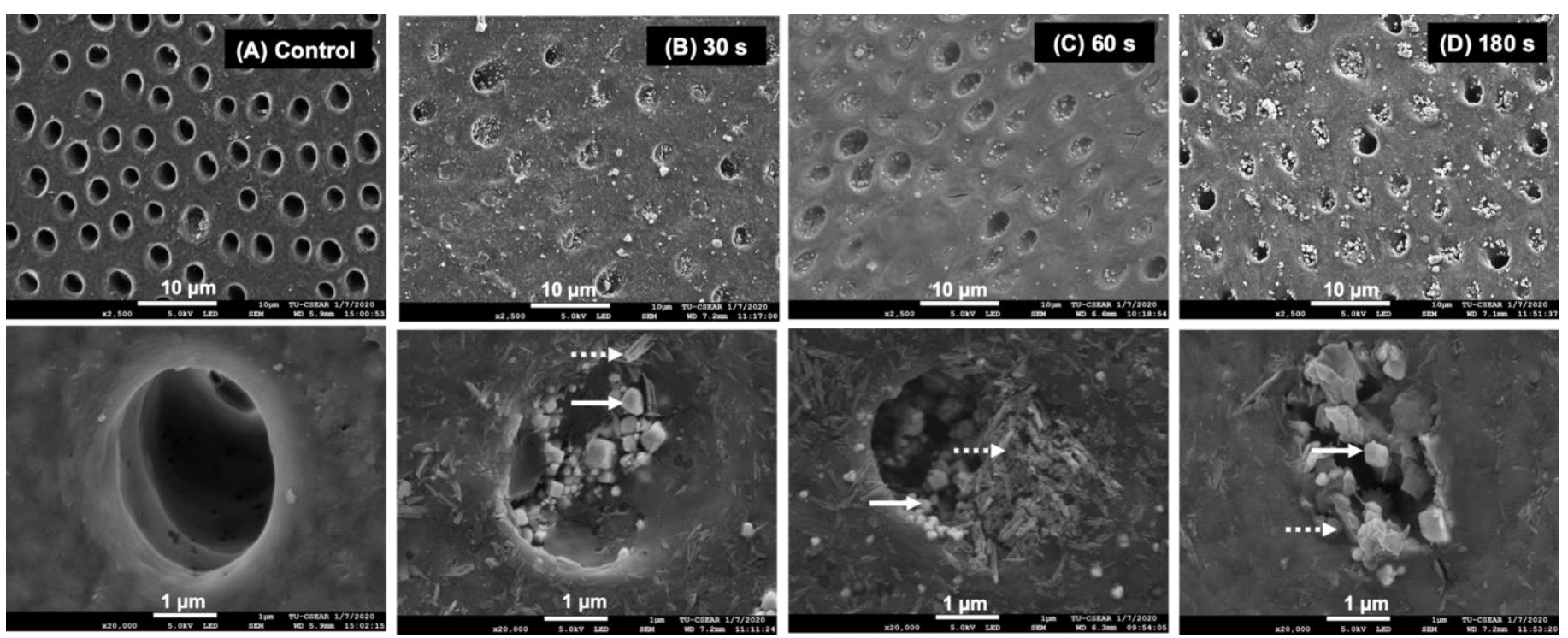

Figure 4. SEM images at low and high magnification of a representative specimen from each group after 2 weeks. (A) The surface of the specimen from the control group showed no mineral precipitation. Precipitation occluding dentinal tubules was detected in the specimens from the (B) 30, (C) 60, and (D) 180 s groups. Irregular shapes (solid arrows) and needle-like precipitates (dash arrows) were observed.
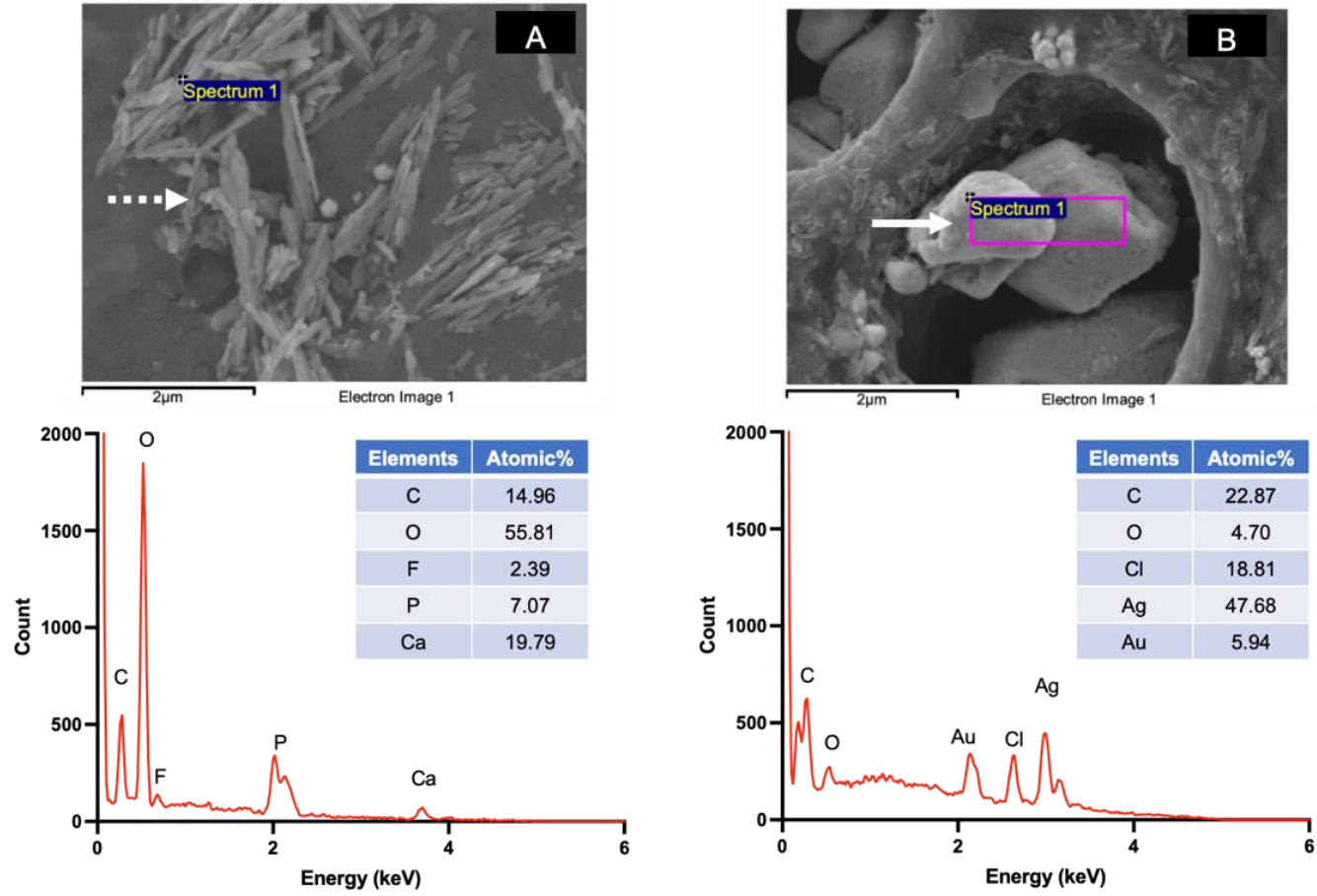

Figure 5. Examples of precipitated crystals and EDX spectra detected on the specimen surface in the 30, 60, and 180 s groups. (A) The calcium phosphate precipitate (needle shape, dashed arrow) containing Ca, F, and P. (B) Crystals containing Ag and $\mathrm{Cl}$ (irregular shape, solid arrow).

3.3. Assessment of the Degree of Mineral Precipitation (Mineral Density) Using Synchrotron Radiation X-ray Tomographic Microscopy (SRXTM)

The reconstructed 3D volume of the specimens from SRXTM images included a radiolucent area (thickness of $\sim 250 \mu \mathrm{m}$ ), which was inferred to be the area of fully demineralized dentin (Figure 6A). However, the demineralized layer of specimens treated with SDF contained dispersed radiodense clusters, which were inferred to be precipitated minerals 
(Figure 6B-D). For the control group, the demineralized layer showed no precipitation (0 vol\%). The degree of mineral precipitation (mineral density, vol\%) of the 30, 60, and $180 \mathrm{~s}$ groups was $65.6 \pm 7.5 \mathrm{vol} \%, 65.8 \pm 2.0 \mathrm{vol} \%$, and $65.2 \pm 8.0 \mathrm{vol} \%$, respectively (Figure $6 \mathrm{E}$ ). The results of the 30,60 , and 180 s groups were all comparable $(p>0.05)$. Videos of the $3 \mathrm{D}$ visualization of representative specimens from the control group and the SDF-treated groups are provided in the Supplementary Materials (Videos S1 and S2).
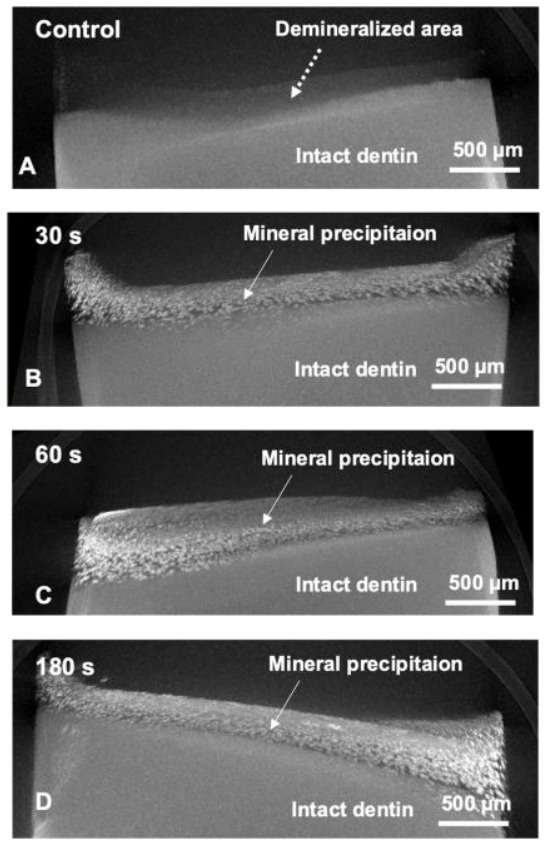

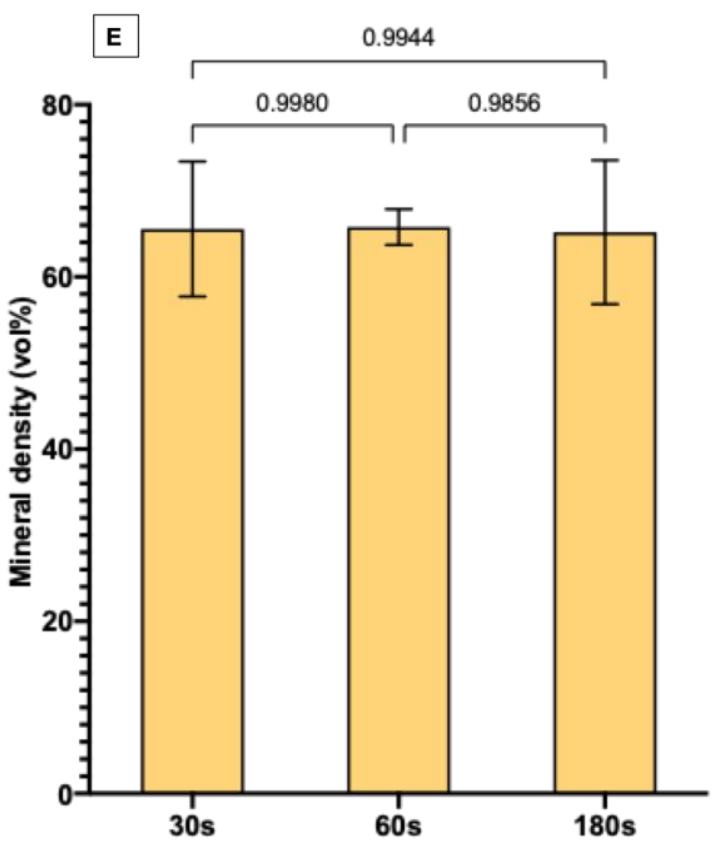

Figure 6. Reconstructed SRXTM images of a representative specimen from each group after immersion in simulated body fluid for 2 weeks. (A) The control group showed a demineralized area ( $250 \mu \mathrm{m}$ depth, dashed arrow) without evident mineral precipitation. (B-D) Reconstructed images from the representative specimen from 30, 60, and 180 s groups, respectively. The images show substantial mineral precipitation in the demineralized area (solid arrows). (E) Mean mineral density obtained from 30, 60, and 180 s groups. Error bars are 95\% CI $(n=6)$. Lines indicate $p>0.05$. Data from the control group were not analyzed because mineral precipitation was not detected. The $3 \mathrm{D}$ visualization images of the specimens are provided in the Supplementary Materials (S1, S2).

\section{Discussion}

SDF is a cost-effective method for controlling the progression of dental caries. However, patients requiring special care due to mental, developmental, or physical disabilities may exhibit very limited cooperation during preventive oral health care practices [14], which may affect the clinical use of the material in these patients. Different studies have recommended application times that range from $30 \mathrm{~s}$ to $3 \mathrm{~min}[15,17]$. Although it has been suggested that the duration of SDF application in carious lesions does not directly correlate with the success of the treatment [16], an explanation for this observation is still lacking. Hence, the current study aimed to assess the effect of applying SDF for different times (30, 60 , or $180 \mathrm{~s}$ ) on the mineral precipitation of demineralized dentin.

The results obtained after 1 week showed that the longest SDF application time (180 s) enabled a rapid increase in mineral precipitation. However, FTIR-ATR, SEM-EDX, and SRXTM results obtained after 2 weeks revealed that mineral precipitation was comparable between the 30,60, and 180 s groups. Hence, the null hypothesis was partially rejected.

The use of simulated body fluid is intended to mimic dentinal fluid in dentin. Simulated body fluid is a solution that is supersaturated with respect to apatite [33]. However, mineral precipitation was only detected in the specimens treated with SDF (Figures 3-5). A possible explanation is that SDF encourages the adsorption of $\mathrm{Ca}$ and $\mathrm{P}$, resulting in mineral apatite formation $[7,34]$. Additionally, the $\mathrm{pH}$ of most SDF products is in the 
alkaline range [35]. This may facilitate suitable conditions [12] for the precipitation of low-solubility fluorohydroxyapatite [36]. SDF also helps to preserve collagen, which acts as a scaffold for mineral precipitation $[8,13]$. Hence, the increase in SDF application time may help to facilitate mineral precipitation in demineralized dentin. This may explain why a significant increase in the $\mathrm{Abs}_{1024} / \mathrm{Abs}_{1636}$ ratio was detected in the $180 \mathrm{~s}$ group before it was observed in the other groups. However, the ratios measured for the 30, 60, and $180 \mathrm{~s}$ groups at each time point were not significantly different in the current study. This may suggest that an application time of 30-180 s allows for sufficient SDF adsorption to dentin and leads to comparable remineralization. This could potentially help to reduce the concerns of clinicians when they need to apply SDF in challenging situations. It should be noted that the current study only employed FTIR to assess mineralization. The use of XPS or XRD may be needed to characterize mineral precipitation in demineralized dentin.

The SEM images of representative specimens from the 30,60, and $180 \mathrm{~s}$ groups after 2 weeks demonstrated similar patterns of mineral precipitation in both the intra-tubular and peri-tubular dentin of the specimens. It has been reported that the primary mineral precipitation after SDF application is formed by calcium phosphates and silver salts $[9,37]$. Crystals containing $\mathrm{Ca}$ and $\mathrm{P}$ were detected in specimens from the experimental groups in the current study, and the precipitation of these calcium phosphate crystals may have contributed to the increase in the FTIR peak ratio. It has also been suggested that fluoride ions from SDF might substitute hydroxyl groups, producing low-solubility and acidresistant fluorohydroxyapatite [11]. Crystals containing $\mathrm{Ca}, \mathrm{P}$, and $\mathrm{F}$ were also detected. In the current study, crystals containing fluoride were not generally detected, which is in accordance with the findings from previous studies $[8,9,38]$. A possible explanation may be that the fluoride level was lower than the detection limit of EDX [9,39].

It has been proposed that the formation of silver salts potentially acts as a protective layer against dental caries and blocks dentinal tubules to protect the pulp-dentin complex $[7,11]$. The EDX results suggest that the metallic crystals that precipitated on the specimen surface may be $\mathrm{AgCl}$ salts [37]. The reaction between SDF and water produces highly soluble silver phosphate (solubility of $6.4 \times 10^{-3} \mathrm{~g} / 100 \mathrm{~mL}$ ) and silver oxide $\left(1.3 \times 10^{-3} \mathrm{~g} / 100 \mathrm{~mL}\right)$, as shown in Equation (1).

$$
2 \mathrm{Ca}_{5}\left(\mathrm{PO}_{4}\right)_{3} \mathrm{OH}+20 \mathrm{Ag}^{+} \rightarrow 2 \mathrm{Ag}_{3} \mathrm{PO}_{4}+10 \mathrm{Ca}^{2+}+\mathrm{Ag}_{2} \mathrm{O}+\mathrm{H}_{2} \mathrm{O}
$$

Silver phosphate and silver oxide can readily react with chloride in an alkaline solution to form silver chloride with lower solubility (solubility of $8.9 \times 10^{-5} \mathrm{~g} / 100 \mathrm{~mL}$ ) [7]. Hence, the precipitation of $\mathrm{AgCl}$ has been commonly reported in published studies [8,11], which is in agreement with the current study. Additionally, the application of SDF is hypothesized to encourage the formation of $\mathrm{CaF}_{2}$, which can act as a fluoride reservoir [11,40]. However, the formation of $\mathrm{CaF}_{2}$ globules was not detected on specimens in the current study. A possible explanation may be that $\mathrm{CaF}_{2}$ was quickly washed away upon rinsing [11,41].

SDF has been shown to promote mineral precipitation in lesions of up to $150 \mu \mathrm{m}$ [42], and the increase in mineral density has helped to reduce the lesion depth from $\sim 250 \mu \mathrm{m}$ to $\sim 100 \mu \mathrm{m}$ [43]. The current study showed that the mineral density in demineralized dentin was increased from $0 \mathrm{vol} \%$ (control group) to $\sim 66 \mathrm{vol} \%$ after SDF application. However, SDF application times of 30,60, and $180 \mathrm{~s}$ showed comparable degrees of mineral precipitation after 2 weeks. This is in agreement with the results of the FTIR studies. The results also showed that high-radiodensity minerals precipitated throughout the entire depth of the demineralized layer $(\sim 250 \mu \mathrm{m})$. However, the precipitation was denser on the outer surface than in the inner area, which could be due to the shrinkage of dentin (Figure 6B-D and Video S2). It is noted that synchrotron radiation X-ray tomographic microscopy (SRXTM) was employed in the current study to quantify the degree of mineral precipitation (mineral density). The benefit of the SRXTM technique is the higher resolution of images (pixel size $\sim 1.44 \mu \mathrm{m}$ ) compared with conventional micro-CT (pixel size $\sim 8 \mu \mathrm{m}$ ) [44]. However, silver is highly radiopaque, which could potentially lead to the overestimation of the mineral density in the demineralized area [45]. Furthermore, shrinkage of dentin was detected after 
SDF application, which may have affected the measurements. Additionally, precipitated crystals that were smaller than the pixel size $(<1.44 \mu \mathrm{m})$ may not have been detected by SRXTM. Hence, the actual degree of mineral precipitation may be different from the calculated values.

The results of the current study may partially explain the lack of correlation between the SDF application time and clinical outcomes [16]. This may be beneficial when treating patients with limited cooperation. However, this was an in vitro study, which cannot mimic the oral environment. In future research, it would be of interest to determine the effect of different application times with a much shorter duration, such as $5-10 \mathrm{~s}$, on the degree of mineral precipitation. Additionally, the different application times may affect the degree of ion penetration into the pulp-dentin complex, which could induce cytotoxic effects or changes of behavior of dental pulp cells $[46,47]$. This could be another important aspect for future studies.

\section{Conclusions}

An SDF application time of $180 \mathrm{~s}$ was associated with a rapid increase in mineral apatite precipitation after 1 week. However, after 2 weeks, the degree of mineral precipitation with different SDF application times (30 s, $60 \mathrm{~s}$, or $180 \mathrm{~s}$ ) was comparable.

Supplementary Materials: The following are available online at https:/ /www.mdpi.com/article/10 .3390/dj9060070/s1, Video S1: Representative specimen of the control group showed no obvious mineral precipitation. Video S2: Representative specimen of the experimental groups showed mineral precipitation on the surface and inside the demineralized area. The precipitation is indicated by green

Author Contributions: Conceptualization, S.S., M.K., P.P., (Prathip Phantumvanit), and P.P. (Piyaphong Panpisut); Data curation, S.S., P.P. (Phakkhananan Pakawanit), and C.R.; Formal analysis, S.S., P.P. (Phakkhananan Pakawanit), C.R., and P.P. (Piyaphong Panpisut); Funding acquisition, M.K., C.R., and P.P. (Piyaphong Panpisut); Investigation, S.S., P.P. (Phakkhananan Pakawanit), C.R., and P.P. (Piyaphong Panpisut); Methodology, S.S., M.K., P.P. (Phakkhananan Pakawanit), C.R., and P.P. (Piyaphong Panpisut); Project administration, M.K., P.P. (Prathip Phantumvanit), and P.P. (Piyaphong Panpisut); Resources, P.P. (Piyaphong Panpisut); Software, P.P. (Piyaphong Panpisut); Supervision, M.K., P.P. (Phakkhananan Pakawanit), C.R., P.P. (Prathip Phantumvanit), and P.P. (Piyaphong Panpisut); Validation, P.P. (Prathip Phantumvanit), and P.P. (Piyaphong Panpisut); Visualization, S.S., P.P. (Phakkhananan Pakawanit), C.R., and P.P. (Piyaphong Panpisut); Writingoriginal draft, S.S., P.P. (Phakkhananan Pakawanit), C.R., P.P. (Prathip Phantumvanit), and P.P. (Piyaphong Panpisut); Writing—review and editing, S.S., M.K., P.P. (Prathip Phantumvanit), and P.P. (Piyaphong Panpisut). All authors have read and agreed to the published version of the manuscript.

Funding: This research received no external funding.

Institutional Review Board Statement: The study was conducted according to the guidelines of the Declaration of Helsinki and approved by Ethics Review Sub-Committee for Research Involving Human Research Subjects of Thammasat University (protocol code 150/2562, date of approval $02 / 10 / 2019)$.

Informed Consent Statement: Patient consent was waived because the patient identification for collecting the extract teeth was not required.

Data Availability Statement: The datasets generated during and/or analyzed during the current study are available from the corresponding author on reasonable request.

Acknowledgments: The authors are grateful for the support from Thammasat University Research Unit in Dental and Bone Substitute Biomaterials, Thammasat University, the Faculty of Dentistry Thammasat University, Thammasat University Hospital, and Thammasat University Center of Scientific Equipment for Advanced Research (TUCSEAR). We sincerely appreciate the technical support from the XTM beamline (BL1.2 W) at Synchrotron Light Research Institute (Public Organization), Nakhon Ratchasima, Thailand. 
Conflicts of Interest: The authors declare no conflict of interest. The funders had no role in the design of the study; in the collection, analyses, or interpretation of data; in the writing of the manuscript; or in the decision to publish the results.

\section{References}

1. GBD Oral Disorders Collaborators. Global, Regional, and National Levels and Trends in Burden of Oral Conditions from 1990 to 2017: A Systematic Analysis for the Global Burden of Disease 2017 Study. J. Dent. Res. 2020, 99, 362-373. [CrossRef] [PubMed]

2. Schwendicke, F. Less Is More? The Long-Term Health and Cost Consequences Resulting from Minimal Invasive Caries Management. Dent. Clin. N. Am. 2019, 63, 737-749. [CrossRef]

3. Fontana, M. Nonrestorative Management of Cavitated and Noncavitated Caries Lesions. Dent. Clin. N. Am. 2019, 63, 695-703. [CrossRef]

4. Urquhart, O.; Tampi, M.P.; Pilcher, L.; Slayton, R.L.; Araujo, M.W.B.; Fontana, M.; Guzman-Armstrong, S.; Nascimento, M.M.; Novy, B.B.; Tinanoff, N.; et al. Nonrestorative Treatments for Caries: Systematic Review and Network Meta-analysis. J. Dent. Res. 2019, 98, 14-26. [CrossRef]

5. Horst, J.A.; Heima, M. Prevention of Dental Caries by Silver Diamine Fluoride. Compend. Contin. Educ. Dent. 2019, 40, 158-163, quiz 164.

6. Chibinski, A.C.; Wambier, L.M.; Feltrin, J.; Loguercio, A.D.; Wambier, D.S.; Reis, A. Silver Diamine Fluoride Has Efficacy in Controlling Caries Progression in Primary Teeth: A Systematic Review and Meta-Analysis. Caries Res. 2017, 51, 527-541. [CrossRef]

7. Zhao, I.S.; Gao, S.S.; Hiraishi, N.; Burrow, M.F.; Duangthip, D.; Mei, M.L.; Lo, E.C.; Chu, C.H. Mechanisms of silver diamine fluoride on arresting caries: A literature review. Int. Dent. J. 2018, 68, 67-76. [CrossRef]

8. Mei, M.L.; Ito, L.; Cao, Y.; Li, Q.L.; Lo, E.C.; Chu, C.H. Inhibitory effect of silver diamine fluoride on dentine demineralisation and collagen degradation. J. Dent. 2013, 41, 809-817. [CrossRef]

9. Mei, M.L.; Lo, E.C.M.; Chu, C.H. Arresting Dentine Caries with Silver Diamine Fluoride: What's Behind It? J. Dent. Res. 2018, 97, 751-758. [CrossRef]

10. Sayed, M.; Matsui, N.; Hiraishi, N.; Inoue, G.; Nikaido, T.; Burrow, M.F.; Tagami, J. Evaluation of discoloration of sound/demineralized root dentin with silver diamine fluoride: In-vitro study. Dent. Mater. J. 2019, 38, 143-149. [CrossRef]

11. Mei, M.L.; Nudelman, F.; Marzec, B.; Walker, J.M.; Lo, E.C.M.; Walls, A.W.; Chu, C.H. Formation of fluorohydroxyapatite with silver diamine fluoride. J. Dent. Res. 2017, 96, 1122-1128. [CrossRef]

12. Hu, S.; Meyer, B.; Duggal, M. A silver renaissance in dentistry. Eur. Arch. Paediatr. Dent. 2018, 19, 221-227. [CrossRef]

13. Firouzmandi, M.; Vasei, F.; Giti, R.; Sadeghi, H. Effect of silver diamine fluoride and proanthocyanidin on resistance of carious dentin to acid challenges. PLoS ONE 2020, 15, e0238590. [CrossRef]

14. American Academy of Pediatric Dentistry. Guideline on Management of Dental Patients with Special Health Care Needs. Pediatr Dent. 2016, 38, 171-176.

15. Crystal, Y.O.; Niederman, R. Silver Diamine Fluoride Treatment Considerations in Children's Caries Management. Pediatr Dent. 2016, 38, 466-471.

16. Horst, J.A.; Ellenikiotis, H.; Milgrom, P.L. UCSF Protocol for Caries Arrest Using Silver Diamine Fluoride: Rationale, Indications and Consent. J. Calif Dent. Assoc. 2016, 44, 16-28.

17. Seifo, N.; Robertson, M.; MacLean, J.; Blain, K.; Grosse, S.; Milne, R.; Seeballuck, C.; Innes, N. The use of silver diamine fluoride (SDF) in dental practice. Br. Dent. J. 2020, 228, 75-81. [CrossRef]

18. Chen, Z.; Cao, S.; Wang, H.; Li, Y.; Kishen, A.; Deng, X.; Yang, X.; Wang, Y.; Cong, C.; Wang, H.; et al. Biomimetic remineralization of demineralized dentine using scaffold of CMC/ACP nanocomplexes in an in vitro tooth model of deep caries. PLoS ONE 2015, 10, e0116553. [CrossRef] [PubMed]

19. British Standard. BS ISO 23317:2014. Implants for Surgery. In Vitro Evaluation for Apatite-Forming Ability of Implant Materials; BSI: British, UK, 2014.

20. Kokubo, T.; Yamaguchi, S. Simulated body fluid and the novel bioactive materials derived from it. J. Biomed. Mater. Res. A 2019, 107, 968-977. [CrossRef]

21. Liu, Y.; Yao, X.; Liu, Y.W.; Wang, Y. A Fourier transform infrared spectroscopy analysis of carious dentin from transparent zone to normal zone. Caries Res. 2014, 48, 320-329. [CrossRef]

22. Zhang, Y.; Wang, Z.; Jiang, T.; Wang, Y. Biomimetic regulation of dentine remineralization by amino acid in vitro. Dent. Mater. 2019, 35, 298-309. [CrossRef]

23. Lopes, C.d.C.A.; Limirio, P.H.J.O.; Novais, V.R.; Dechichi, P. Fourier transform infrared spectroscopy (FTIR) application chemical characterization of enamel, dentin and bone. Appl. Spectrosc. Rev. 2018, 53, 747-769. [CrossRef]

24. Yin, I.X.; Yu, O.Y.; Zhao, I.S.; Mei, M.L.; Li, Q.L.; Tang, J.; Lo, E.C.M.; Chu, C.H. Inhibition of dentine caries using fluoride solution with silver nanoparticles: An in vitro study. J. Dent. 2020, 103, 103512. [CrossRef] [PubMed]

25. Berzina-Cimdina, L.; Borodajenko, N. Research of Calcium Phosphates Using Fourier Transform Infrared Spectroscopy. In Infrared Spectroscopy-Materials Science, Engineering and Technology; InTech: Rijeka, Croatian, 2012; pp. 123-148.

26. Vidal Bde, C.; Mello, M.L. Collagen type I amide I band infrared spectroscopy. Micron 2011, 42, 283-289. [CrossRef] 
27. Ghimire, H.; Venkataramani, M.; Bian, Z.; Liu, Y.; Perera, A.G.U. ATR-FTIR spectral discrimination between normal and tumorous mouse models of lymphoma and melanoma from serum samples. Sci. Rep. 2017, 7, 16993. [CrossRef] [PubMed]

28. Riaz, T.; Zeeshan, R.; Zarif, F.; Ilyas, K.; Muhammad, N.; Safi, S.Z.; Rahim, A.; Rizvi, S.A.A.; Rehman, I.U. FTIR analysis of natural and synthetic collagen. Appl. Spectrosc. Rev. 2018, 53, 703-746. [CrossRef]

29. Mei, M.L.; Ito, L.; Cao, Y.; Lo, E.C.; Li, Q.L.; Chu, C.H. An ex vivo study of arrested primary teeth caries with silver diamine fluoride therapy. J. Dent. 2014, 42, 395-402. [CrossRef]

30. Vlassenbroeck, J.; Masschaele, B.; Cnudde, V.; Dierick, M.; Pieters, K.; Van Hoorebeke, L.; Jacobs, P. Octopus 8: A High Performance Tomographic Reconstruction Package for X-ray Tube and Synchrotron micro-CT. In Advances in X-ray Tomography for Geomaterials; John Wiley \& Sons: Hoboken, NJ, USA, 2006; pp. 167-173.

31. Limaye, A. Drishti: A volume exploration and presentation tool. In Developments in X-Ray Tomography VIII; International Society for Optics and Photonics: San Diego, CA, USA, 2012; p. 85060X. [CrossRef]

32. Panpisut, P.; Suppapatpong, T.; Rattanapan, A.; Wongwarawut, P. Monomer conversion, biaxial flexural strength, apatite forming ability of experimental dual-cured and self-adhesive dental composites containing calcium phosphate and nisin. Dent. Mater. J. 2021, 40, 399-406. [CrossRef]

33. Kokubo, T.; Takadama, H. How useful is SBF in predicting in vivo bone bioactivity? Biomaterials 2006, 27, 2907-2915. [CrossRef] [PubMed]

34. Chu, C.H.; Mei, L.; Seneviratne, C.J.; Lo, E.C. Effects of silver diamine fluoride on dentine carious lesions induced by Streptococcus mutans and Actinomyces naeslundii biofilms. Int. J. Paediatr. Dent. 2012, 22, 2-10. [CrossRef]

35. Mei, M.L.; Li, Q.L.; Chu, C.H.; Yiu, C.K.; Lo, E.C. The inhibitory effects of silver diamine fluoride at different concentrations on matrix metalloproteinases. Dent. Mater. 2012, 28, 903-908. [CrossRef]

36. Aoba, T. Solubility properties of human tooth mineral and pathogenesis of dental caries. Oral Dis. 2004, 10, 249-257. [CrossRef] [PubMed]

37. Cai, J.; Burrow, M.F.; Manton, D.J.; Tsuda, Y.; Sobh, E.G.; Palamara, J.E.A. Effects of silver diamine fluoride/potassium iodide on artificial root caries lesions with adjunctive application of proanthocyanidin. Acta Biomater. 2019, 88, 491-502. [CrossRef]

38. Li, Y.; Liu, Y.; Psoter, W.J.; Nguyen, O.M.; Bromage, T.G.; Walters, M.A.; Hu, B.; Rabieh, S.; Kumararaja, F.C. Assessment of the Silver Penetration and Distribution in Carious Lesions of Deciduous Teeth Treated with Silver Diamine Fluoride. Caries Res. 2019, 53, 431-440. [CrossRef] [PubMed]

39. Sayed, M.; Matsui, N.; Uo, M.; Nikaido, T.; Oikawa, M.; Burrow, M.F.; Tagami, J. Morphological and elemental analysis of silver penetration into sound/demineralized dentin after SDF application. Dent. Mater. 2019, 35, 1718-1727. [CrossRef] [PubMed]

40. Vogel, G.L. Oral fluoride reservoirs and the prevention of dental caries. Monogr. Oral Sci. 2011, 22, 146-157. [CrossRef]

41. Lou, Y.L.; Botelho, M.G.; Darvell, B.W. Reaction of silver diamine [corrected] fluoride with hydroxyapatite and protein. J. Dent. 2011, 39, 612-618. [CrossRef]

42. Punyanirun, K.; Yospiboonwong, T.; Kunapinun, T.; Thanyasrisung, P.; Trairatvorakul, C. Silver diamine fluoride remineralized artificial incipient caries in permanent teeth after bacterial pH-cycling in-vitro. J. Dent. 2018, 69, 55-59. [CrossRef]

43. Zhao, I.S.; Mei, M.L.; Li, Q.L.; Lo, E.C.M.; Chu, C.H. Arresting simulated dentine caries with adjunctive application of silver nitrate solution and sodium fluoride varnish: An in vitro study. Int. Dent. J. 2017, 67, 206-214. [CrossRef]

44. Zhao, I.S.; Mei, M.L.; Burrow, M.F.; Lo, E.C.; Chu, C.H. Effect of silver diamine fluoride and potassium iodide treatment on secondary caries prevention and tooth discolouration in cervical glass ionomer cement restoration. Int. J. Mol. Sci. 2017, 18, 340. [CrossRef]

45. Romero, M.; Lippert, F. Indirect caries-preventive effect of silver diamine fluoride on adjacent dental substrate: A single-section demineralization study. Eur. J. Oral Sci. 2021, 129, e12751. [CrossRef]

46. Kim, S.; Nassar, M.; Tamura, Y.; Hiraishi, N.; Jamleh, A.; Nikaido, T.; Tagami, J. The effect of reduced glutathione on the toxicity of silver diamine fluoride in rat pulpal cells. J. Appl. Oral Sci. 2021, 29, e20200859. [CrossRef]

47. Marrelli, M.; Codispoti, B.; Shelton, R.M.; Scheven, B.A.; Cooper, P.R.; Tatullo, M.; Paduano, F. Dental Pulp Stem Cell Mechanoresponsiveness: Effects of Mechanical Stimuli on Dental Pulp Stem Cell Behavior. Front. Physiol. 2018, 9, 1685. [CrossRef] 